\title{
Bioinformatics approach to mRNA markers discovery for detection of circulating tumor cells in patients with gastrointestinal cancer
}

\author{
Manuel Valladares-Ayerbes MD ${ }^{\mathrm{a}}$, Silvia Díaz-Prado $\mathrm{PhD}^{\mathrm{b}}$, Marga Reboredo MD, \\ Vanessa Medina Bs, Sc ${ }^{a}$, Pilar Iglesias-Díaz MD ${ }^{c}$, Maria J. Lorenzo-Patiño MD ${ }^{c}$, \\ Rosario G. Campelo MD ${ }^{\mathrm{a}}$, Mar Haz Tch ${ }^{\mathrm{a}}$, Isabel Santamarina Tch ${ }^{\mathrm{a}}$, Luis M. Antón- \\ Aparicio MD, $\mathrm{PhD}^{\mathrm{a}}$
}

\author{
${ }^{a}$ Medical Oncology and Institute for Biomedical Research (INIBIC), Juan Canalejo University Hospital, Spain \\ ${ }^{b}$ Medicine Department, La Coruñ a University, Spain \\ ${ }^{c}$ Pathology Department, Juan Canalejo University Hospital, Spain
}

\begin{abstract}
Background: Detection of tumor cells in the blood, or minimal deposits in distant organs as bone marrow, could be important to identify cancer patients at high risk of relapse or disease progression. Quantitative polymerase chain reaction (PCR) amplification of tissue or tumor selective mRNA is the most powerful tool for the detection of this circulating or occult metastatic cells. Our study aims to identify novel gastrointestinal cancer-specific markers for circulating tumor cell detection. Method: Phase I preclinical study was performed by means of computational tools for expression analysis. In silico data were used to identify and prioritize molecular markers highly expressed in gastrointestinal cancers but absent in hematopoietic-derived libraries. Selected genes were evaluated by means of qRT-PCR in gastrointestinal cancer and hematopoietic cell-lines, normal human bone marrows and bloods, tumor tissue, and blood from cancer patients. Results: Novel and known mRNA markers for circulating tumor cell detection in gastrointestinal cancer have been identified. Among all the genes assessed, PKP3, AGR2, S100A16, S100A6, LGALS4, and CLDN3 were selected and assays based on blood qRT-PCR were developed. Reliably qRT-PCR assays for the novel targets plakophilin 3 (PKP3) and anterior gradient-2 (AGR2) to identify blood-borne cells in cancer patients were developed. Conclusions: Novel and known gastrointestinal-specific mRNA markers for circulating tumor cells have been identified through in silico analysis and validated in clinical material. qRT-PCR assay targeted to PKP3 and AGR2 mRNAs might be helpful to detect circulating tumor cells in patients with gastrointestinal cancer.
\end{abstract}

Keywords:

Neoplasm circulating cells; Metastasis; Biological tumor markers; Reverse transcriptase polymerase chain reaction; Gene expression pattern analysis; Databases nucleic acid; Epithelial cells; Tumor cell lines; Anterior gradient 2 homolog (Xenopus laevis) protein; Plakophilin 3 


\section{Introduction}

Cancer of the gastrointestinal (GI) system encompasses a great proportion of tumor-related deaths in the world. Stage at the time of diagnostic and suitability for curative surgery remains the most important prognostic factors for digestive tract tumors. However, distant and loco-regional relapses frequently occur in spite of resection and adjuvant therapy. Colorectal cancer is the second leading cause of cancer deaths in the western countries. Most of these patients are diagnosed with localized disease, but their average 5year survival is 50-60\% in European countries [1]. For patients with other common GI malignancies, the options for curative resections are limited and survival remains poor, especially for esophageal and gastric carcinomas and pancreatic cancer.

Circulating tumor cells and occult metastasis (micrometastasis) are considered early stages in the progression of metastatic cascade in epithelial cancer. Detection of tumor cells in the blood or minimal deposits in distant organs as bone marrow could be important to identify patients at high risk of relapse or disease progression.

PCR amplification of tissue or tumor-selective mRNA is the most powerful tool for detection of this circulating or occult metastatic cells. Cytokeratin 20, carcinoembryonic antigen (CEA), and epidermal growth factor receptor (EGFR) are among the most frequent mRNA markers used in different reversetranscriptase polymerase-chain reaction (RT-PCR) assays in GI-cancer patients [[2], [3]]. However, cancer genetic heterogeneity, down-regulation of mRNA marker in tumor cells, or low-level transcription of selected target in the hematopoietic compartment could compromise both sensitivity and specificity of molecular methods.

Selection of novel gastrointestinal cancer-specific transcripts and development of multi-marker quantitative RT-PCR assays are clearly outstanding research questions [[4], [5]].

EGFR has been found to be overexpressed in a high proportion of gastrointestinal cancer and confers a poor prognosis [6]. Development of a quantitative assay to detect EGFR-expressing circulating tumor cells could be relevant for prognostic assessment, monitor response, or even thought select target therapy [7].

RT-PCR assays for different glycosyltransferases have been developed for tumor cells detection in blood for breast cancer and melanoma patients [8]. Beta-1,6- $N$-acetylglucosaminyltransferase V (GNT-V, MGAT5; Hs.200/Mm.161; EC 4.1.155) expression in colorectal cancer had been correlated with metastasis and poor prognosis [9]. Thus GNT-V could represent a suitable mRNA biomarker for circulating tumor cell detection in gastrointestinal cancer patients.

The present study aims to identify novel GI cancer-specific markers for circulating tumor cells (CTC) detection. The development of mRNA-based tools for CTC biomarkers was done following the proposed guidelines of the Early Detection Research Network (EDRN) by the National Cancer Institute [10]. Phase I preclinical study was performed by means of computational tools for expression analysis. In order to validate the usefulness of this in silico approach to identify tumor cells markers, selected genes were evaluated in cell lines and clinical specimens. Finally, qRT-PCR assays for the novel targets plakophilin 3 (PKP3) and anterior gradient-2 (AGR2) to identifiy blood-borne cells in cancer patients were developed. 


\section{Materials and methods}

\subsection{Digital differential display and computational tools}

Digital differential display (DDD) [11] is an in silico data-mining resource of the National Centre for Biotechnology Information (NCBI) for comparing sequence-based gene representation profiles. DDD is based on the UniGene concept and provides the genes that are represented at different levels in the selected cDNA libraries using statistical tests. DDD was used to identify molecular markers highly expressed in GI cancers but absent in blood and bone marrow-derived EST libraries. A set of cDNA libraries from blood and bone marrow $(n=13)$ was selected and it was compared with three pools of colon $(n=10)$, gastric $(n=13)$, and pancreatic $(n=5)$ carcinoma cDNA libraries. Each set was selected to include the broad heterogeneity of every tumor type and includes the minimum possible number of libraries generated from normalized or subtracted cDNAs.

Tags with statistically significant $(p<0.05$; Fisher's exact test) higher expression in GI cancer libraries were detected and each EST was identified by UniGene cluster.

ESTs whose expression was 10 or more times higher in each set of cancer libraries in comparison with blood and bone marrow-derived EST libraries were selected. As a second filter step, we selected those tags with undetectable or low representation in hematopoietic control libraries, defined as an expression count equal or less than four in DDD output.

Furthermore, the tissue distribution and tumor specificity of every gene selected were analyzed using representation profiles obtained with virtual northern blot [VN, Ref. [12]]. For each combination of tissue and pathologic status, VN shows a spot image representing the expression level of the selected gene and numeric columns. These represent the number of ESTs or SAGE tags corresponding to the gene divided by the total number of ESTs or SAGE tags in all libraries with the given tissue/histology. The statistical significance of the observed counts is measured using Bayesian analysis. Values $(p)$ less or equal to 0.05 were considered significant [13]. Virtual northern blots for EGFR [14] and GNT-V [15] were also obtained. Functional data about the different gene selected were extracted from Gene Ontology (GO) annotations accessed in the Cancer Gene Anatomy Project (CGAP) database [[12], [16]].

\subsection{Cell lines}

As a surrogated model of gastrointestinal cancer, the following human tumor cell-lines were used: colorectal carcinoma Gp5d, LoVo, DLD1, LS513, HT29, OJC4, OJC5, OJC6; gastric adenocarcinoma OE19, and pancreatic carcinoma OJC1. In addition, hematopoietic cell lines Jurkat, KG1, and K562 were analyzed.

The cell-lines OJC1, OJC4, OJC5, and OJC6 were developed in our laboratory from clinical specimens and they have been fully characterized [17]. All the cell lines were maintained in DMEM (Dulbecco's modified Eagle's medium-high glucose) and MegaCell ${ }^{\mathrm{TM}}$ RPMI-1640 mediums (both provided by Sigma-Aldrich) supplemented with $10 \%$ fetal calf serum inactivated, $1 \%$ penicillin, $1 \%$ streptomycin, and $1 \%$ amphotericin at $37{ }^{\circ} \mathrm{C}$ in $5 \% \mathrm{CO}_{2}$. Cells from adherent cultures were recovered with $1 \%$ trypsin-1\% EDTA cell dissociating reagent. Cell pellets from suspension cultures were obtained. 


\subsection{Clinical tissue specimens and blood preparation}

Formalin-fixed and paraffin-embedded tissue (FFPE) from colon cancer specimens $(n=16)$ were obtained from the Pathology Department of the Juan Canalejo University Hospital. Array tissue apparatus, provided by Durviz, was used to obtain tissue cores with $2 \mathrm{~mm}$ diameter, selecting an area enriched for tumor tissue. These FFPE cores were used for specific mRNA detection of gene selected using DDD and computational tools.

Blood samples were prospectively collected from an additional cohort of gastrointestinal carcinoma patients $(n=11)$ and from age and sex matched non-carcinoma donors $(n=10)$. All the patients included were in the advanced stage, including eight colorectal cancer stage IV, one stage III rectal cancer before any treatment, and two pancreatic adenocarcinomas (stages II and IV). Blood were collected in $10 \mathrm{ml}$ EDTA-containing tubes. To eliminate skin-plug contamination of the blood sample from initial venipuncture, the first several milliliters of blood were discarded. Samples were subjected to lysis and stabilized, in less than $1 \mathrm{~h}$ after blood withdrawal, in guanidinium-based RNA/DNA stabilization reagent for blood/bone marrow (Roche, Mannheim, Germany) at 10\% (v/v) without cell and plasma separation. The mixtures were stored at $-80{ }^{\circ} \mathrm{C}$ until mRNA extraction. Isolation reagent for blood and bone marrow (Roche, Mannheim, Germany) was used for mRNA extraction.

The study was approved by the Institutional Review Board of the Ethic Committee of Clinical Investigation of Galicia (Spain) and written informed consent was obtained from all patients.

\subsection{RNA extraction and $q R T-P C R$}

Isolation of total RNA from cell cultures was performed using High Pure RNA Isolation Kit (Roche, Mannheim, Germany) following manufacturer's instructions. From each cell line at $70 \%$ confluence, $10^{6}$ cells were obtained for RNA isolation. Total RNA was treated with DNase I.

RNA isolation from FFPE tissue cores of each specimen was performed with Optimum ${ }^{\mathrm{TM}}$ FFPE RNA Isolation Kit (Ambion, Diagnostics); manufacturer's protocol was followed.

RNA isolated from human normal bone marrows were purchased from BD Biosciences-Clontech. Total RNA was derived from three different pools of normal human bone marrows $(n=23)$.

mRNA isolation from blood samples was performed with mRNA Isolation Kit for Blood/Bone Marrow (Roche, Mannheim, Germany), following manufacturer's recommendations. Briefly, total nucleic acid fraction was adsorbed to magnetic glass particle and poly(A)+ RNA was captured by using biotinlabeled oligo(dT) and streptavidin-coated magnetic particles. Each mRNA preparation was eluted in $12 \mu \mathrm{l}$ RNase-free redistilled water. Purified poly (A)+ RNA was further processed in RT-PCR or stored at -80 ${ }^{\circ} \mathrm{C}$ until use. RNA integrity was confirmed by $2 \%$ agarose gel electrophoresis and stained with ethidium bromide.

\section{5. cDNA synthesis}

Reverse-transcription (RT) was performed from total cellular and bone marrow RNA using SuperScript ${ }^{\mathrm{TM}}$ First-Strand Synthesis System for RT-PCR (Invitrogen ${ }^{\mathrm{TM}}$, USA) up to a total volume of 20 $\mu \mathrm{l} \times 1 \mu \mathrm{g}$ of total RNA, $2.5 \mathrm{nM}$ random hexamers, $0.5 \mathrm{mM} \mathrm{dNTP}$ mix, and $3 \mu \mathrm{l}$ of DEPC-treated water were denatured at $65{ }^{\circ} \mathrm{C}$ for $5 \mathrm{~min}$ and chilled on ice for at least $1 \mathrm{~min}$. On the other hand, $2 \mu \mathrm{l}$ of $10 \times \mathrm{RT}$ buffer, $5 \mathrm{mM} \mathrm{MgCl}$, $0.01 \mathrm{M}$ DTT, and $40 \mathrm{U}$ of RNaseOUT Recombinant Ribonuclease Inhibitor were mixed, collected by centrifugation, and incubated at $25^{\circ} \mathrm{C}$ for $2 \mathrm{~min}$. After incubation, $50 \mathrm{U}$ of SuperScript ${ }^{\mathrm{TM}} \mathrm{RT}$ ) were added and incubated at $25^{\circ} \mathrm{C}$ for $10 \mathrm{~min}, 42{ }^{\circ} \mathrm{C}$ for $50 \mathrm{~min}$, and $70{ }^{\circ} \mathrm{C}$ for $15 \mathrm{~min}$ in a Thermocycler (Gene Amp PCR System 9700, Applied Biosystem). Finally, samples were chilled on ice and incubated with $2 \mathrm{U}$ of RNAse $\mathrm{H}$ for $20 \mathrm{~min}$ at $37^{\circ} \mathrm{C}$ before proceeding to amplification the target 
cDNA. For mRNA obtained from blood we follow the same procedure and $0.02 \mu \mathrm{g}$ were subjected to cDNA synthesis. Positive and negative controls were included in each experiment. RNA extraction, reverse transcription-PCR assay setup, and post-reverse transcription-PCR product analysis were carried out in separate designated rooms to prevent cross-contamination. cDNA was quantified and assessed for purity using a GENIOUS UV spectrophotometer. cDNA concentration was measured at $260 \mathrm{~nm}$. Also A260/A280 relation was calculated to know cDNA quality.

\subsection{Quantitative real-time reverse transcription-PCR analysis}

Real-time PCR analysis was performed, using primers and conditions shown in Table 1, on LightCycler $^{\circledR} 480$ Instrument (Roche, Mannheim, Germany) using LightCycler 480 SYBR Green I Master (Roche, Mannheim, Germany). PCR reaction consisted of $10 \mu \mathrm{l}$ of Master Mix $2 \times$ conc., $0.35 \mu \mathrm{M}$ of each forward and reverse primer, template cDNA and PCR-grade water up to a final volume of $20 \mu \mathrm{in}$ the LightCycler 480 Multiwell Plate 96. Multiwell Plate was centrifuged at $3000 \mathrm{rpm}$ for 2 min and was loaded in the LightCycler 480 Instrument until the PCR program started. An initial activation at $95{ }^{\circ} \mathrm{C}$ for 5 min was followed by an amplification target sequence 50 cycles of $95{ }^{\circ} \mathrm{C}$ for $10 \mathrm{~s}, 54-60{ }^{\circ} \mathrm{C}$ (depending on the primers pair used) for $10 \mathrm{~s}$, and $72{ }^{\circ} \mathrm{C}$ (depending on the amplicon size amplified) were used. For melting curve analysis 1 cycle of $95{ }^{\circ} \mathrm{C}$ for $5 \mathrm{~s}, 70^{\circ} \mathrm{C}$ for $15 \mathrm{~s}$, and $95{ }^{\circ} \mathrm{C}$ for $1 \mathrm{~s}$ was used. Finally, a cooling step was used at $40^{\circ} \mathrm{C}$ for $10 \mathrm{~s}$. 
Table 1. qRT-PCR — primers and conditions: primers sequences, conditions and annealing temperature of real-time quantitative RTPCR used to amplify selected genes

\begin{tabular}{|c|c|c|c|c|}
\hline Primers & Sequence & Length (mer) & $\% \mathrm{GC}$ & Annealing temperature $\left({ }^{\circ} \mathrm{C}\right)$ \\
\hline PKP3 1R & $5^{\prime}$-ggatgaaaggttccacagga-3' & 20 & 50 & 60 \\
\hline PKP3 2F & $5^{\prime}$-ggcccgcagccttcaggccgtgcc-3' & 24 & 79 & \\
\hline GNT-V 1F & $5^{\prime}$-att ggc aag cca act ctg a-3' & 19 & 47 & 55 \\
\hline GNT-V 1R & $5^{\prime}$-ttg agg tca aca gtc cac aca-3' & 21 & 48 & \\
\hline AGR2 2F & $5^{\prime}-\operatorname{ctg}$ gec aga gat acc aca gtc- $3^{\prime}$ & 21 & 57 & 54 \\
\hline AGR2 2R & $5^{\prime}$-agt tgg tca ccc caa cct- $3^{\prime}$ & 19 & 58 & \\
\hline S100A16 2F & $5^{\prime}$-tgg aga gga ggc aga ctg ag- $3^{\prime}$ & 20 & 60 & 54 \\
\hline S100A16 2R & $5^{\prime}$-cca cca gga caa tga ctg c-3' & 19 & 58 & \\
\hline LGALS4 1F & $5^{\prime}$-aac ctt caa ccc gcc tgt- $3^{\prime}$ & 18 & 56 & 54 \\
\hline LGALS4 1R & $5^{\prime}-$ gag ccc acc ttg aag ttg at- $3^{\prime}$ & 20 & 50 & \\
\hline $\mathrm{LCN} 21 \mathrm{~F}$ & $5^{\prime}$-cag gac tcc acc tca gac ct- $3^{\prime}$ & 20 & 60 & 54 \\
\hline LCN2 1R & $5^{\prime}$-cac ata cca ctt cec ctg ga-3' & 20 & 55 & \\
\hline MGC3047 1F & $5^{\prime}$-cca gaa gtc ggg aaa gtc aa-3' & 20 & 50 & 54 \\
\hline MGC3047 1R & $5^{\prime}$-ctc act cet gta aag cat ctg g-3' & 22 & 50 & \\
\hline EFNB1 1F & $5^{\prime}$-tca tga agg ttg ggc aag a-3' & 19 & 47 & 54 \\
\hline EFNB1 1R & $5^{\prime}$-gtg tgg cca tct tga cag tg-3' & 20 & 55 & \\
\hline ASS $1 \mathrm{~F}$ & $5^{\prime}$-aag ctt ggg gcc aaa aag-3' & 18 & 50 & 54 \\
\hline ASS1R & $5^{\prime}$-gta gcg gtc ctc ata cag tgc-3' & 21 & 57 & \\
\hline CLDN3 2F & $5^{\prime}$-cca tta tcc ggg act tct aca ac- $3^{\prime}$ & 23 & 48 & 60 \\
\hline CLDN3 2R & $5^{\prime}-$ gac acg agc agc aga gca-3' & 18 & 61 & \\
\hline EGFR 2F & $5^{\prime}$-cag cca ccc ata tgt acc atc-3' & 21 & 52 & 60 \\
\hline EGFR 2R & $5^{\prime}-a a c$ tt ggg cga cta tct gc- $3^{\prime}$ & 20 & 50 & \\
\hline S100A6 2F & $5^{\prime}$-act gcg aca cag ccc atc- $3^{\prime}$ & 18 & 61 & 60 \\
\hline S100A6 2R & $5^{\prime}$-gaa gat ggc cac gag gag-3' & 18 & 61 & \\
\hline HPRT 1F & $5^{\prime}$-tga cet tga ttt att ttg cat acc-3' & 24 & 33 & 60 \\
\hline HPRT 1R & $5^{\prime}$-cga gca aga cgt tca gtc ct-3' & 20 & 55 & \\
\hline
\end{tabular}

We verified that amplifications and the expected size of each PCR product were specific. $1.8 \%$ agarose gel electrophoresis of all PCR products revealed a single band that corresponded to the singleamplified products as predicted by the melting curve analysis of the PCR. The amplification efficiency was determined for both target and housekeeping genes and was equal (99-100\%).

PCR primers for mRNA amplification of the different selected genes were carefully designed using the web-based ProbeFinder software (Universal ProbeLibrary Design Center) [18] or via Roche Applied Science home page [19]. PCR primers have been positioned to span exon-intron boundaries, reducing the risk of detecting genomic DNA. Primers were purchased from Invitrogen ${ }^{\mathrm{TM}}$ (USA) and Roche (Mannheim, Germany).

Suitable selection of housekeeping gene(s) was performed using Human Endogenous Control Gene Panel (TATAA Biocenter, Sweden). The Excel macro GeNorm VBA applet for Microsoft Excel was used to determine the gene(s) with most correlated expression in the set of samples. Homo sapiens HPRT (Hypoxanthine-guanine phosphoribosyltransferase) were used as internal control for blood, bone marrow, and cell-lines samples. Also housekeeping gene was used to verify integrity of RNA and efficacy of reverse transcription. Any specimen with inadequate HPRT mRNA was excluded from the study. 
Data analysis was performed with LigthCycler 480 Relative Quantification software (Roche, Mannheim, Germany). Relative levels of expression were calculated by the $2^{-\Delta \Delta C t}$ method [20]. Each assay was done at least in triplicate and included marker-positive and marker-negative controls and reagent with no template controls.

\subsection{DNA sequencing}

At least one PCR product coming from each Real-time PCR experiment was used as template DNA. Products were purified by enzymatic method (ExoSAP-IT, Amersham USB). DNA sequencing was performed in a reference facility on ABI 3700 (Applied Biosystems) using Big Dye terminators. Forward and reverse primers used in sequencing reactions were the same as for the Real-time PCR, see Table 1.

\subsection{Statistical analysis}

Statistical significance of differences was evaluated at the $95 \%$ confidence level by non-parametric statistic, Mann-Whitney $U$-test; $p$-value $<0.05$ were considered to be significant. Receiver operating characteristics (ROC) curve analysis was used to evaluate the diagnostic discrimination power of the selected differentially expressed genes. The threshold value for optimal sensitivity and specificity of PKP3 and AGR2 mRNA relative expression levels (R.E.L.) was also determined by ROC analysis. All of the statistical analyses were performed using the SPSS 12.0 for Windows.

\section{Results}

\subsection{Search for gastrointestinal tumor-associated biomarkers using computational tools}

Digital differential display (DDD) data were used to identify and prioritize molecular markers highly expressed in GI cancers but absent in blood and bone marrow-derived libraries. The pools used in this analysis, their ID libraries and the ESTs clustered are shown in Table 2. Differential over representation were found for 34 genes in colorectal cancer libraries, for 96 in gastric cancer libraries, and for 144 in pancreatic cancer libraries in comparison with hematopoietic libraries. Potential up-regulated targets of note from this study include, among others, genes involved in cell adhesion and cytoskeleton, cell signaling, growth factor activity, ribosomal proteins, calcium-related metabolism, heat shock proteins as well as hypothetical proteins.

Table 2. Digital differential display: cDNA libraries: Pool of libraries, their identification numbers (IDs) and the expressed sequence tags (ESTs) clustered used in the digital differential display (DDD) bioinformatics tool

\begin{tabular}{llr}
\hline Pool & Lib (IDs) & Clustered ESTs \\
\hline & & 43918 \\
Colorectal cancer & $842,841,840,882,1540,988,956,987,1447,486$ & 44581 \\
Gastric cancer & $10324,10311,10310,10306,10325,10302,10301,10299,10305,14437,1449$, & 42014 \\
Pancreatic cancer & 721,733 & 51208 \\
Blood and bone marrow & $7038,7037,6976,6975,8975,11923,931,5948,5566,9724,8613,14381,765$ & \\
\hline
\end{tabular}


From this set, we specifically selected those ESTs whose expression was at least 10-fold higher in each set of cancer libraries and undetectable or low represented in hematopoietic control libraries, defined as an expression count equal or less than four in DDD output. After these filters, we obtained a collection of 30, 58, and 91 genes in colon, gastric and pancreatic cancer-derived cDNA libraries, respectively (Fig. 1 and Table 3 ).

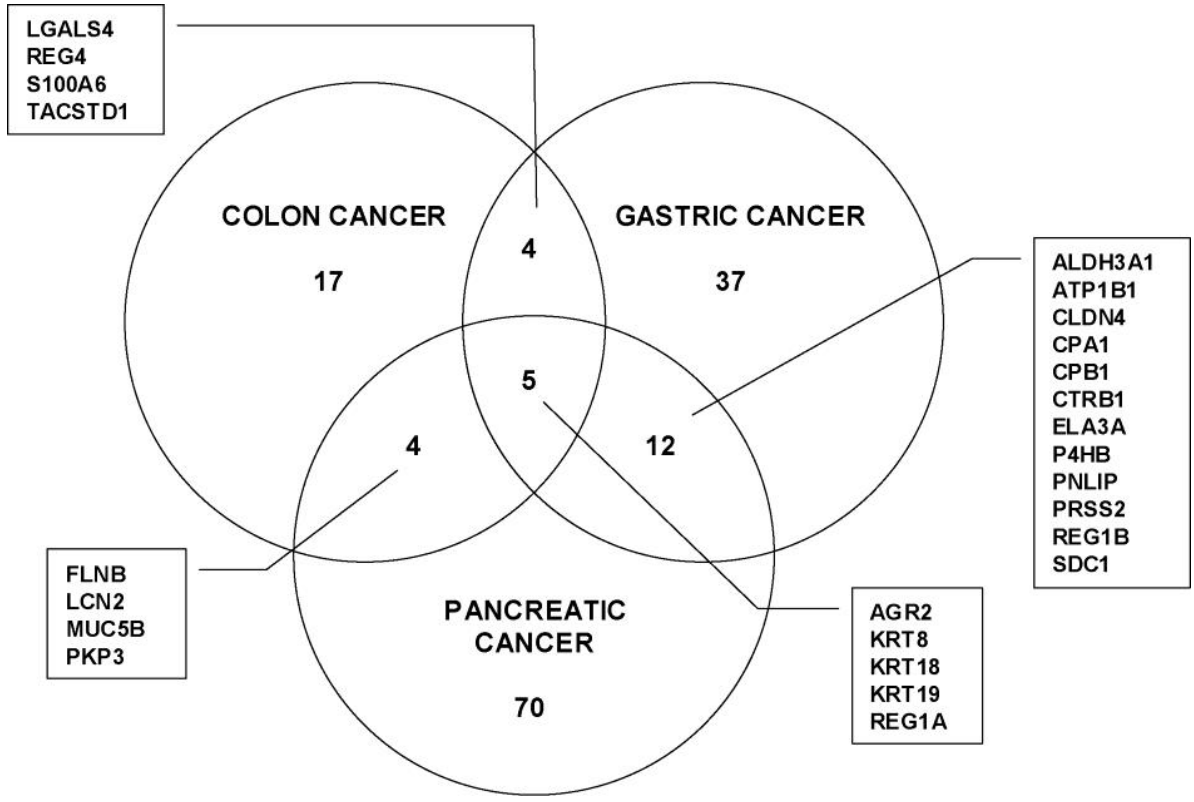

Fig. 1. Overexpressed genes in colon, gastric and pancreatic cancer-derived cDNA libraries: Venn diagram showing overexpressed genes in colon, gastric and pancreatic cancer-derived cDNA libraries. Only those genes whose expression was at least 10-fold higher in each set of cancer libraries and undetectable or low represented in hematopoietic control libraries are shown.

Table 3. Up-regulated genes in gastrointestinal tumors according to digital differential display (DDD)

\begin{tabular}{lll}
\hline Gene name Gene Description & EnT & $\begin{array}{l}\text { ESTene \# Function } \\
\text { counts in } \begin{array}{l}\text { EST counts in } \\
\text { hematopoietic } \\
\text { tumor } \\
\text { libraries }\end{array}\end{array}$ \\
\hline
\end{tabular}

A: Colorectal

\begin{tabular}{|c|c|}
\hline AGR2 & $\begin{array}{l}\text { Anterior gradient } 2 \text { homolog (Xenopus } \\
\text { laevis) }\end{array}$ \\
\hline ASS & Argininosuccinate synthetase \\
\hline CEACAM5 & $\begin{array}{l}\text { Carcinoembryonic antigen-related cell } \\
\text { adhesión molecule } 5\end{array}$ \\
\hline CLDN3 & Claudin 3 \\
\hline DIPA & $\begin{array}{l}\text { Hepatitis delta antigen-interacting } \\
\text { protein A }\end{array}$ \\
\hline EFNB1 & Ephrin-B1 \\
\hline FLNB & $\begin{array}{l}\text { Filamin B, beta (actin binding protein } \\
278 \text { ) }\end{array}$ \\
\hline GDF15 & Growth differentiation factor 15 \\
\hline GMDS & GDP-mannose 4,6-dehydratase \\
\hline $\mathrm{H} 1 \mathrm{FX}$ & H1 histone family, member $\mathrm{X}$ \\
\hline
\end{tabular}

\begin{tabular}{|c|c|c|c|}
\hline Hs. 226391 & Secretory protein & 14 & 42 \\
\hline Hs. 160786 & Enzyme & 24 & 24 \\
\hline Hs.220529 & Receptor/surface/membrane & 22 & 22 \\
\hline Hs. 25640 & Receptor/surface/membrane & 39 & 39 \\
\hline Hs.66713 & Binding protein & 20 & 20 \\
\hline Hs. 144700 & Binding protein & 20 & 20 \\
\hline Hs. 81008 & Binding protein & 26 & 26 \\
\hline Hs. 296638 & Secretory protein & 41 & 41 \\
\hline Hs. 105435 & Enzyme & 22 & 22 \\
\hline Hs.75307 & Binding protein & 14 & 56 \\
\hline
\end{tabular}




\begin{tabular}{|c|c|c|c|c|c|}
\hline KLF5 & Kruppel-like factor 5 (intestinal) & Hs. 84728 & Binding protein & 18 & 18 \\
\hline KRT18 & Keratin 18 & Hs.406013 & Receptor/surface/membrane & 42 & 126 \\
\hline KRT19 & Keratin 19 & Hs.309517 & Receptor/surface/membrane & 37 & 37 \\
\hline KRT8 & Keratin 8 & Hs.356123 & Receptor/surface/membrane & 78 & 78 \\
\hline LCN2 & Lipocalin 2 (oncogene 24p3) & Hs. 204238 & Secretory protein & 19 & 19 \\
\hline LGALS4 & $\begin{array}{l}\text { Lectin, galactoside-binding, soluble, } 4 \\
\text { (galectin 4) }\end{array}$ & Hs.5302 & Binding protein & 30 & 30 \\
\hline LOC374395 & Similar to RIKEN cDNA 1810059G22 & Hs.381134 & Hypothetical protein & 21 & 21 \\
\hline MGC3047 & Hypothetical protein & Hs.76239 & Hypothetical protein & 25 & 25 \\
\hline MUC5B & Mucin 5, subtype B, tracheobronchial & Hs. 103707 & Secretory protein & 24 & 24 \\
\hline PKP3 & Plakophilin 3 & Hs. 148074 & Receptor/surface/membrane & 28 & 28 \\
\hline REG1A & $\begin{array}{l}\text { Regenerating islet-derived } 1 \text { alpha } \\
\text { (pancreatic stone protein, pancreatic } \\
\text { thread protein) }\end{array}$ & Hs.49407 & Secretory protein & 27 & 27 \\
\hline REG4 & $\begin{array}{l}\text { Regenerating islet-derived family, } \\
\text { member } 4\end{array}$ & Hs. 105484 & Secretory protein & 25 & 25 \\
\hline RHOB & Ras homolog gene family, member B & Hs.406064 & Enzyme & 29 & 29 \\
\hline S100A16 & S100 calcium binding protein A16 & Hs.8182 & Binding protein & 23 & 23 \\
\hline S100A6 & $\begin{array}{l}\text { S100 calcium binding protein A6 } \\
\text { (calcyclin) }\end{array}$ & Hs. 275243 & Binding protein & 10 & 39 \\
\hline SAFB & Scaffold attachment factor B & Hs. 23978 & Binding protein & 18 & 18 \\
\hline SLC39A8 & $\begin{array}{l}\text { Solote carrier family } 39 \text { (zinc } \\
\text { transporter), member } 8\end{array}$ & Hs. 284205 & Zinc transporter & 14 & 28 \\
\hline TACSTD1 & $\begin{array}{l}\text { Tumor-associated calcium signal } \\
\text { transducer } 1\end{array}$ & Hs.692 & Receptor/surface/membrane & 19 & 19 \\
\hline WARP & $\begin{array}{l}\text { Von Willebrand factor A domain- } \\
\text { related protein }\end{array}$ & Hs.449009 & Secretory protein & 22 & 22 \\
\hline ZFP36L2 & Zinc finger protein $36, \mathrm{C} 3 \mathrm{H}$ type-like 2 & Hs.78909 & Binding protein & 12 & 25 \\
\hline \multicolumn{6}{|l|}{ B: Gastric } \\
\hline $\mathrm{A} 2 \mathrm{M}$ & Alpha-2-macroglobulin & Hs.74561 & Binding protein & 37 & 37 \\
\hline AGR2 & $\begin{array}{l}\text { Anterior gradient } 2 \text { homolog (Xenopus } \\
\text { laevis) }\end{array}$ & Hs.226391 & Secretory protein & 35 & 106 \\
\hline ALDH1A1 & $\begin{array}{l}\text { Aldehyde dehydrogenase } 1 \text { family, } \\
\text { member A1 }\end{array}$ & Hs.76392 & Enzyme & 11 & 44 \\
\hline ALDH3A1 & $\begin{array}{l}\text { Aldehyde dehydrogenase } 3 \text { family, } \\
\text { member A1 }\end{array}$ & Hs. 575 & Enzyme & 45 & 45 \\
\hline ANKRD9 & Ankyrin repeat domain 9 & Hs.432945 & Binding protein & 43 & 43 \\
\hline ATP1B1 & $\begin{array}{l}\text { ATPase, } \mathrm{Na}^{+} / \mathrm{K}^{+} \text {transporting, beta } 1 \\
\text { polypeptide }\end{array}$ & Hs.78629 & Enzyme & 25 & 25 \\
\hline CLDN4 & Claudin 4 & Hs.5372 & Receptor/surface/membrane & 27 & 27 \\
\hline CPA1 & Carboxypeptidase A1 (pancreatic) & Hs. 2879 & Enzyme & 53 & 53 \\
\hline CPB1 & Carboxypeptidase B1 (tissue) & Hs.437028 & Enzyme & 20 & 20 \\
\hline CREB3L1 & $\begin{array}{l}\text { cAMP responsive element binding } \\
\text { protein 3-like } 1\end{array}$ & Hs.405961 & Biniding protein & 22 & 22 \\
\hline CTRB1 & Chymotrypsinogen B1 & Hs.449833 & Enzyme & 29 & 29 \\
\hline DDX41 & $\begin{array}{l}\text { DEAD (Asp-Glu-Ala-Asp) box } \\
\text { polypeptide } 41\end{array}$ & Hs. 274317 & Binding protein & 14 & 59 \\
\hline DECR2 & $\begin{array}{l}\text { 2,4-Dienoyl CoA reductase } 2, \\
\text { peroxisomal }\end{array}$ & Hs. 15898 & Enzyme & 19 & 19 \\
\hline ELA3A & Enastase $3 \mathrm{~A}$, pancreatic (protease $\mathrm{E}$ ) & Hs.471034 & Enzyme & 27 & 27 \\
\hline GLTSCR2 & $\begin{array}{l}\text { Glioma tumor suppressor candidate } \\
\text { region gene } 2\end{array}$ & Hs. 421907 & Unknown function & 11 & 47 \\
\hline GPX2 & $\begin{array}{l}\text { Glutathione peroxidase } 2 \\
\text { (gastrointestinal) }\end{array}$ & Hs. 2704 & Enzyme & 21 & 21 \\
\hline GRN & Granulin & Hs. 180577 & Binding protein & 29 & 29 \\
\hline
\end{tabular}




\begin{tabular}{|c|c|c|c|c|c|}
\hline ID1 & $\begin{array}{l}\text { Inhibitor of DNA binding 1, dominant } \\
\text { negative helix-loop-helix protein }\end{array}$ & Hs.410900 & Binding protein & 19 & 19 \\
\hline JARID1C & $\begin{array}{l}\text { Jumonji, AT-rich interactive domain 1C } \\
\text { (RBP2-like) }\end{array}$ & Hs. 103381 & Binding protein & 27 & 27 \\
\hline KLF13 & Kruppel-like factor 13 & Hs.7104 & Binding protein & 18 & 18 \\
\hline KREMEN2 & $\begin{array}{l}\text { Kringle containing transmembrane } \\
\text { protein } 2\end{array}$ & Hs.351474 & Receptor/surface/membrane & 25 & 25 \\
\hline KRT18 & Keratin 18 & Hs.406013 & Receptor/surface/membrane & 10 & 32 \\
\hline KRT19 & Keratin 19 & Hs.309517 & Receptor/surface/membrane & 21 & 21 \\
\hline KRT8 & Keratin 8 & Hs. 356123 & Receptor/surface/membrane & 146 & 146 \\
\hline LDHA & Lactate dehydrogenase A & Hs.2795 & Enzyme & 17 & 383 \\
\hline LGALS4 & $\begin{array}{l}\text { Lectin, galactoside-binding, soluble, } 4 \\
\text { (galectin 4) }\end{array}$ & Hs.5302 & Binding protein & 19 & 19 \\
\hline LISCH7 & $\begin{array}{l}\text { Liver-specific bHLH-Zip transcription } \\
\text { factor }\end{array}$ & Hs.312129 & Binding protein & 22 & 22 \\
\hline LRFN4 & $\begin{array}{l}\text { Leucine-rich repeat and fibronectin type } \\
\text { III domain containing } 4\end{array}$ & Hs. 148438 & Binding protein & 43 & 43 \\
\hline LYZ & Lysozyme (renal amyloidosis) & Hs.234734 & Enzyme & 16 & 32 \\
\hline MEIS3 & $\begin{array}{l}\text { Meis 1, myeloid ecotropic viral } \\
\text { integration site } 1 \text { homolog } 3 \text { (Mouse) }\end{array}$ & Hs.380923 & Binding protein & 19 & 19 \\
\hline MUC1 & Mucin 1, transmembrane & Hs.89603 & Secretory protein & 26 & 26 \\
\hline MYEOV & Myeloma overexpressed gene & Hs. 436000 & Unknown function & 21 & 21 \\
\hline MYH11 & $\begin{array}{l}\text { Myosin, heavy polypeptide } 11 \text {, smooth } \\
\text { muscle }\end{array}$ & Hs.78344 & Binding protein & 31 & 31 \\
\hline NQO1 & $\begin{array}{l}\text { NAD(P)H dehydrogenase, quinone } 1 \\
\text { (NQO1) }\end{array}$ & Hs.406515 & Enzyme & 10 & 42 \\
\hline $\mathrm{P} 4 \mathrm{HB}$ & $\begin{array}{l}\text { Procollagen-proline, 2-oxoglutarate 4- } \\
\text { dioxygenase (proline 4-hydroxylase) }\end{array}$ & Hs.410578 & Binding protein & 14 & 56 \\
\hline PGA5 & Pepsinogen 5, group I & Hs.432854 & Enzyme & 122 & 122 \\
\hline PGC & Progastricsin (pepsinogen C) & Hs. 1867 & Enzyme & 95 & 95 \\
\hline PLK2 & Polo-like kinase2 (Drosophila) & Hs.398157 & Enzyme & 29 & 29 \\
\hline PME-1 & Protein phsphatase methylesterase- 1 & Hs.63304 & Enzyme & 15 & 30 \\
\hline PNLIP & Pancreatic lipase & Hs. 102876 & Enzyme & 20 & 20 \\
\hline PRSS2 & Protease, serine, 2 (trypsine 2) & Hs.511525 & Enzyme & 91 & 91 \\
\hline PYCR1 & Pyrroline-5-carboxylate reductase 1 & Hs.458332 & Enzyme & 11 & 71 \\
\hline REG1A & $\begin{array}{l}\text { Regenerating islet-derived } 1 \text { alpha } \\
\text { (pancreatic stone protein, pancreatic } \\
\text { thread protein) }\end{array}$ & Hs.49407 & Secretory protein & 55 & 55 \\
\hline REG1B & $\begin{array}{l}\text { Regenerating islet-derived } 1 \text { beta } \\
\text { (pancreatic stone protein, pancreatic } \\
\text { thread protein) }\end{array}$ & Hs. 4158 & Secretory protein & 23 & 23 \\
\hline REG4 & $\begin{array}{l}\text { Regenerating islet-derived family, } \\
\text { member } 4\end{array}$ & Hs. 105484 & Secretory protein & 68 & 68 \\
\hline RGS5 & Regulator of G-protein signalling 5 & Hs. 24950 & Binding protein & 30 & 30 \\
\hline S100A6 & $\begin{array}{l}\text { S100 calcium binding protein A6 } \\
\text { (calcyclin) }\end{array}$ & Hs. 275243 & Binding protein & 11 & 44 \\
\hline SDC1 & Syndecan 1 & Hs.82109 & Binding protein & 13 & 27 \\
\hline SERPINB6 & $\begin{array}{l}\text { Serine (or cysteine)proteinase inhibitor, } \\
\text { clade B (ovalbumin), member } 6\end{array}$ & Hs. 41072 & Enzyme & 13 & 27 \\
\hline SKB1 & SKB1 homolog (S. pombe) & Hs.367854 & Binding protein & 18 & 18 \\
\hline SPARCL1 & SPARC-like 1 (mast9, Kevin) & Hs.75445 & Secretory protein & 20 & 20 \\
\hline TACSTD1 & $\begin{array}{l}\text { Tumor-associated calcium signal } \\
\text { transducer } 1\end{array}$ & Hs.692 & Receptor/surface/membrane & 29 & 29 \\
\hline TGFB1I4 & $\begin{array}{l}\text { Transforming growth factor beta 1- } \\
\text { induced transcript } 4\end{array}$ & Hs. 114360 & Secretory protein & 23 & 23 \\
\hline THBS3 & Thrombospondin 3 & Hs. 169875 & Binding protein & 20 & 20 \\
\hline
\end{tabular}




\begin{tabular}{|c|c|c|c|c|c|}
\hline TM4SF3 & $\begin{array}{l}\text { Transmembrane } 4 \text { superfamily member } \\
3\end{array}$ & Hs. 84072 & Receptor/surface/membrane & 16 & 32 \\
\hline TRY2 & Trypsin II precursor & Hs.367767 & Enzyme & 24 & 24 \\
\hline WBSCR21 & $\begin{array}{l}\text { Williams Beuren síndrome chromosome } \\
\text { region } 21\end{array}$ & Hs. 182476 & Binding protein & 20 & 20 \\
\hline ZNF499 & Zinc finger protein 499 & Hs.445346 & Binding protein & 45 & 45 \\
\hline \multicolumn{6}{|l|}{ C: Pancreatic } \\
\hline $\mathrm{ABCD} 1$ & $\begin{array}{l}\text { ATP-binding cassette, sub-family D } \\
\text { (ALD), member } 1\end{array}$ & Hs. 159546 & Binding protein & 34 & 34 \\
\hline ADAM15 & $\begin{array}{l}\text { A disintegrin and metalloproteinase } \\
\text { domain } 15 \text { (metargidin) }\end{array}$ & Hs.312098 & Enzyme & 31 & 31 \\
\hline AGR2 & $\begin{array}{l}\text { Anterior gradient } 2 \text { homolog (Xenopus } \\
\text { laevis) }\end{array}$ & Hs.226391 & Secretory protein & 42 & 127 \\
\hline AHSA1 & $\begin{array}{l}\text { AHA1, activator of heat shock } 90 \mathrm{kDa} \\
\text { protein ATPase homolog } 1 \text { (yeast) }\end{array}$ & Hs.204041 & Enzyme & 23 & 23 \\
\hline ALDH3A1 & $\begin{array}{l}\text { Aldehyde dehydrogenase } 3 \text { family, } \\
\text { member A } 1\end{array}$ & Hs. 575 & Enzyme & 85 & 85 \\
\hline APG4D & $\begin{array}{l}\text { APG4D autophagy } 4 \text { homolog D ( } S \text {. } \\
\text { cerevisiae) }\end{array}$ & Hs.512799 & Enzyme & 52 & 52 \\
\hline ATAD3A & $\begin{array}{l}\text { ATPase family, AAA domain } \\
\text { containing } 3 \mathrm{~A}\end{array}$ & Hs.467479 & Enzyme & 21 & 21 \\
\hline ATP1B1 & $\begin{array}{l}\text { ATPase, } \mathrm{Na}^{+} / \mathrm{K}^{+} \text {transporting, beta } 1 \\
\text { polypeptide }\end{array}$ & Hs.78629 & Enzyme & 23 & 23 \\
\hline C1S & $\begin{array}{l}\text { Complement component } 1, \mathrm{~s} \\
\text { subcomponent }\end{array}$ & Hs. 458355 & Enzyme & 23 & 23 \\
\hline CAPN1 & Calpain $1(\mathrm{mu} / \mathrm{I})$ large subunit & Hs.356181 & Enzyme & 31 & 31 \\
\hline CCT7 & $\begin{array}{l}\text { Chaperonin containing TCP1, subunit } 7 \\
\text { (eta) }\end{array}$ & Hs.368149 & Binding protein & 22 & 89 \\
\hline CDC42EP4 & $\begin{array}{l}\text { CDC42 effector protein (Rho GTPase } \\
\text { binding) } 4\end{array}$ & Hs.3903 & Binding protein & 180 & 180 \\
\hline CLDN4 & Claudin 4 & Hs.5372 & Receptor/surface/membrane & 37 & 37 \\
\hline CPA1 & Carboxypeptidase A1 (pancreatic) & Hs. 2879 & Enzyme & 55 & 55 \\
\hline CPB1 & Carboxypeptidase B1 (tissue) & Hs. 437028 & Enzyme & 28 & 28 \\
\hline CRABP2 & Cellular retinoic acid binding protein 2 & Hs. 183650 & Binding protein & 21 & 21 \\
\hline CTRB1 & Chymotrypsinogen B1 & Hs.74502 & Enzyme & 18 & 18 \\
\hline CTSD & $\begin{array}{l}\text { Cathepsin D (lysosomal aspartyl } \\
\text { protease) }\end{array}$ & Hs.34375 & Enzyme & 10 & 31 \\
\hline DHRSX & $\begin{array}{l}\text { Dehydrogenase/reductase (SDR family) } \\
\text { X-linked }\end{array}$ & Hs.11779 & Enzyme & 53 & 53 \\
\hline DKK3 & Dickkopf homolog 3 (Xenopus laevis) & Hs. 130865 & Secretory protein & 99 & 99 \\
\hline DLGAP4 & $\begin{array}{l}\text { Discs, large (Drosophila) homolog- } \\
\text { associated protein } 4\end{array}$ & Hs. 249600 & Binding protein & 18 & 36 \\
\hline DRAP1 & $\begin{array}{l}\text { DR1-associated protein } 1 \text { (negative } \\
\text { cofactor } 2 \alpha \text { ) }\end{array}$ & Hs.356742 & Binding protein & 24 & 24 \\
\hline EEF1A2 & $\begin{array}{l}\text { Eukaryotic translation elongation factor } \\
1 \text { alpha } 2\end{array}$ & Hs.433839 & Binding protein & 59 & 59 \\
\hline EGLN2 I & Egl nine homolog 2 (C. elegans) & Hs.324277 & Binding protein & 29 & 29 \\
\hline EIF4G1 & $\begin{array}{l}\text { Eukaryotic translation initiation factor } 4 \\
\text { gamma, } 1\end{array}$ & Hs. 433750 & Binding protein & 13 & 26 \\
\hline ELA3A & Enastase $3 \mathrm{~A}$, pancreatic (protease E) & Hs.471034 & Enzyme & 33 & 33 \\
\hline ELF3 & $\begin{array}{l}\text { E74-like factor } 3 \text { (ets domain } \\
\text { transcription factor, ephitelial specific) }\end{array}$ & Hs.67928 & Binding protein & 20 & 20 \\
\hline EPHA2 & EphA2 & Hs.171596 & Receptor/surface/membrane & 19 & 19 \\
\hline FKBP4 & FK506 binding protein $4,59 \mathrm{kDa}$ & Hs. 848 & Binding protein & 31 & 63 \\
\hline FLJ23322 & Hypothetical protein & Hs.387601 & Hypothetical protein & 58 & 58 \\
\hline FLNB & $\begin{array}{l}\text { Filamin B, beta (actin binding protein } \\
278 \text { ) }\end{array}$ & Hs. 81008 & Binding protein & 30 & 30 \\
\hline
\end{tabular}




\begin{tabular}{|c|c|c|c|c|c|}
\hline FLNC & $\begin{array}{l}\text { Filamin C, gamma (actin binding } \\
\text { protein 280) }\end{array}$ & Hs.58414 & Binding protein & 67 & 67 \\
\hline GCG & Glucagon & Hs.423901 & Enzyme & 74 & 74 \\
\hline GSN & Gelsolin (amyloidosis, Finnish type) & Hs. 446537 & Binding protein & 10 & 30 \\
\hline HAS3 & Hyaluronan synthase 3 & Hs.85962 & Enzyme & 23 & 23 \\
\hline HMGA1 & High mobility group AT-hook 1 & Hs.57301 & Binding protein & 21 & 108 \\
\hline IDS & Iduronate 2 -sulfatase (Hunter syndrome) & Hs.303154 & Enzyme & 21 & 21 \\
\hline IFI27 & Interferon, alpha-inducible protein 27 & Hs. 278613 & Receptor/surface/membrane & 25 & 25 \\
\hline IGFBP6 & $\begin{array}{l}\text { Insulin-like growth factor binding } \\
\text { protein } 6\end{array}$ & Hs. 274313 & Binding protein & 22 & 22 \\
\hline ITGB4 & Integrin, beta 4 & Hs.85266 & Cell adhesion molecules & 19 & 19 \\
\hline ITGB6 & Integrin, beta 6 & Hs.57664 & Cell adhesion molecules & 23 & 23 \\
\hline JUP & Junction plakoglobin & Hs. 2340 & Cell adhesion molecules & 57 & 57 \\
\hline KRT13 & Keratin 13 & Hs.433871 & Receptor/surface/membrane & 28 & 28 \\
\hline KRT17 & Keratin 17 & Hs. 2785 & Receptor/surface/membrane & 37 & 112 \\
\hline KRT18 & Keratin 18 & Hs.406013 & Receptor/surface/membrane & 116 & 349 \\
\hline KRT19 & Keratin 19 & Hs.309517 & Receptor/surface/membrane & 163 & 163 \\
\hline KRT5 & Keratin 5 & Hs. 433845 & Receptor/surface/membrane & 79 & 79 \\
\hline KRT6A & Keratin 6A & Hs.367762 & Receptor/surface/membrane & 37 & 37 \\
\hline KRT7 & Keratin 7 & Hs.23881 & Receptor/surface/membrane & 39 & 79 \\
\hline KRT8 & Keratin 8 & Hs. 356123 & Receptor/surface/membrane & 223 & 223 \\
\hline KRTHB1 & Keratin, hair, Basic, 1 & Hs. 170925 & Receptor/surface/membrane & 34 & 34 \\
\hline LAMC2 & Laminin, gamma 2 & Hs. 54451 & Cell adhesion molecule & 27 & 27 \\
\hline LCN2 & Lipocalin 2 (encogen $24 \mathrm{p} 3)$ & Hs. 204238 & Secretory protein & 55 & 55 \\
\hline LOC142678 & Skeletrophin & Hs. 135805 & Binding protein & 41 & 41 \\
\hline LRP1 & $\begin{array}{l}\text { Low density lipoprotein-related protein } \\
1 \text { (alpha-2-macroglobulin receptor) }\end{array}$ & Hs. 162757 & Receptor/surface/membrane & 13 & 27 \\
\hline LUM & Lumican & Hs. 406475 & Binding protein & 10 & 63 \\
\hline LY6E & Lymphocyte antigen 6 complex, locus E & Hs. 77667 & Receptor/surface/membrane & 21 & 42 \\
\hline MGAT4B & $\begin{array}{l}\text { Mannosyl (alpha-1,3)-glycoprotein beta- } \\
1,4-N \text {-acetylglucosaminyltransferase, } \\
\text { isoenzyme B }\end{array}$ & Hs. 437277 & Enzyme & 69 & 69 \\
\hline MGC10471 & Hypothetical protein & Hs. 24998 & Hypothetical protein & 109 & 109 \\
\hline MGC2776 & Hypothetical protein & Hs. 335550 & Hypothetical protein & 49 & 49 \\
\hline MGLL & Monoglyceride lipase & Hs. 409826 & Enzyme & 21 & 21 \\
\hline MRPL49 & Mitochondrial ribosomal protein L-49 & Hs.75859 & Ribosomal protein & 11 & 59 \\
\hline MRPS12 & Mitochondrial ribosomal protein S12 & Hs.411125 & Ribosomal protein & 23 & 23 \\
\hline MUC5B & Mucin 5, subtype B, tracheobronchial & Hs. 103707 & Secretory protein & 34 & 34 \\
\hline NID & Nidogen (enactin) & Hs.356624 & Binding protein & 82 & 82 \\
\hline NRBP & Nuclear receptor binding protein & Hs. 272736 & Binding protein & 16 & 50 \\
\hline NUMBL & Numb homolog (Drosophila)-like & Hs.326953 & Unknown function & 20 & 20 \\
\hline P4HB & $\begin{array}{l}\text { Procollagen-proline, 2-oxoglutarate 4- } \\
\text { dioxygenase (proline 4-hydroxylase) }\end{array}$ & Hs. 410578 & Enzyme & 14 & 57 \\
\hline PAK4 & p21 (CDKN!A)-activated kinase 4 & Hs. 20447 & Binding protein & 26 & 26 \\
\hline PCBD & $\begin{array}{l}\text { 6-Pyruvoyl-tetrahydropterin } \\
\text { synthase/dimerization cofactor of } \\
\text { hepatocyte nuclear factor } 1 \text { alpha } \\
\text { (TCF1) }\end{array}$ & Hs.3192 & Enzyme & 33 & 33 \\
\hline PCQAP & $\begin{array}{l}\text { PC2 (positive cofactor 2, multiprotein } \\
\text { complex) glutamina/Q-rich-associated } \\
\text { protein }\end{array}$ & Hs. 410347 & $\begin{array}{l}\text { Transcription regulatory } \\
\text { protein }\end{array}$ & 21 & 43 \\
\hline PKP3 & Plakophilin 3 & Hs. 148074 & Receptor/surface/membrane & 23 & 23 \\
\hline PLAT & Plasminogen activator, tissue & Hs.274404 & Enzyme & 32 & 32 \\
\hline
\end{tabular}




\begin{tabular}{|c|c|c|c|c|c|c|}
\hline PLEC1 & $\begin{array}{l}\text { Plactin 1, intermediate filament binding } \\
\text { protein } 500 \mathrm{kDa}\end{array}$ & Hs.79706 & Binding protein & 40 & 40 & 1 \\
\hline PNLIP & Pancreatic lipase & Hs. 102876 & Enzyme & 24 & 24 & 0 \\
\hline PRSS2 & Protease, serine, 2 (trypsin 2) & Hs. 511525 & Enzyme & 94 & 94 & 1 \\
\hline PRSS3 & Protease, serine, 3 (mesotrypsin) & Hs.435699 & Enzyme & 31 & 31 & 1 \\
\hline RAC1 & $\begin{array}{l}\text { Ras-related C } 3 \text { botulinum toxin } \\
\text { substrate } 1 \text { (rho family, small GTP } \\
\text { binding protein Rac1) }\end{array}$ & Hs. 413812 & Binding protein & 18 & 73 & 4 \\
\hline REG1A & $\begin{array}{l}\text { Regenerating islet-derived } 1 \text { alpha } \\
\text { (pancreatic stone protein, pancreatic } \\
\text { thread protein) }\end{array}$ & Hs.49407 & Secretory protein & 46 & 46 & 1 \\
\hline REG1B & $\begin{array}{l}\text { Regenerating islet-derived } 1 \text { beta } \\
\text { (pancreatic stone protein, pancreatic } \\
\text { thread protein) }\end{array}$ & Hs. 4158 & Secretory protein & 24 & 24 & 0 \\
\hline RGS19IP1 & $\begin{array}{l}\text { Regulador of G-protein signalling } 19 \\
\text { interacting protein } 1\end{array}$ & Hs.6454 & Receptor/surface/membrane & 12 & 24 & 2 \\
\hline SCD & $\begin{array}{l}\text { Stearoyl-CoA desaturase (delta-9- } \\
\text { desaturase) }\end{array}$ & Hs.119597 & Enzyme & 29 & 59 & 2 \\
\hline SCNN1A & $\begin{array}{l}\text { Sodium channel, nonvoltage-gated } 1 \\
\text { alpha }\end{array}$ & Hs. 446415 & Binding protein & 22 & 22 & 0 \\
\hline SDC1 & Syndecan 1 & Hs.82109 & Receptor/surface/membrane & 12 & 24 & 2 \\
\hline SERPINA1 & $\begin{array}{l}\text { Serine (or cysteine) proteinase inhibitor, } \\
\text { clade A (alpha- } 1 \text { antiproteinase, } \\
\text { antitrypsin), member } 1\end{array}$ & Hs.297681 & Enzyme & 26 & 26 & 0 \\
\hline SFRP2 & Secreted frizzled-related protein 2 & Hs.31386 & Secretory protein & 29 & 29 & 0 \\
\hline SSFA2 & Sperm specific antigen 2 & Hs.438599 & Receptor/surface/membrane & 41 & 41 & 0 \\
\hline STMN3 & Stathmin-like 3 & Hs. 285753 & Binding protein & 12 & 63 & 5 \\
\hline SUGT1 & $\begin{array}{l}\text { SGT1, supressor of G2 allele of SKP1 } \\
\text { (S. cerevisiae) }\end{array}$ & Hs. 107776 & Binding protein & 24 & 24 & 1 \\
\hline TIMM50 & $\begin{array}{l}\text { Translocase of inner mitochondrial } \\
\text { membran } 50 \text { homolog (yeast) }\end{array}$ & Hs.355819 & Enzyme & 17 & 51 & 3 \\
\hline TMEPAI & $\begin{array}{l}\text { Transmembrane, prostate androgen- } \\
\text { induced RNA }\end{array}$ & Hs. 83883 & Unknown function & 20 & 40 & 2 \\
\hline
\end{tabular}

Hits (known ESTs) showing $\geq 10$-fold differences in the tumor-derived libraries in comparison with normal blood and bone marrow tissue-derived cDNA libraries are shown: colorectal (A), gastric (B) and pancreatic (C). Gene name, gene description, gene function and UniGene number of each hit are also shown. EST counts in tumors and hematopoietics libraries are shown. The last column of the tables indicates the number of fold differences in the gastrointestinal tumor-derived libraries in comparison with normal tissuederived cDNA libraries. When EST counts in hematopoietics libraries were zero, EST counts in tumors are considered as fold difference.

Among all of the up-regulated genes obtained, we identified several known genes which have previously been shown to be overexpressed in gastrointestinal tumors, and proposed as micrometastasis markers [21] as keratins 8, 18, and 19, CEACAM5, and tumor-associated calcium signal transducer 1 (TACSTD1). The tissue distribution and tumor specificity were analyzed using representation profiles obtained with virtual northern (Table 4). Based on in silico data we could predict that some of the markers could be expressed in the hematopoietic compartment. 
Table 4. Expression of selected markers in gastrointestinal cancers, bone marrow and white blood cells: EST and SAGE data

\begin{tabular}{|c|c|c|c|c|c|c|c|c|}
\hline & \multicolumn{2}{|l|}{ Colon cancer } & \multicolumn{2}{|c|}{ Gastric cancer } & \multicolumn{2}{|c|}{ Pancreatic cancer } & Bone marrow & \multirow{2}{*}{$\frac{\text { Blood }}{\text { SAGE data }}$} \\
\hline & EST Data & SAGE data & EST data & SAGE data & EST data & SAGE data & EST data SAGE data & \\
\hline PKP3 & $35 / 170084$ & $27 / 643586$ & $11 / 70532$ & $74 / 448716$ & $23 / 75487$ & $13 / 189999$ & $0 / 44611 \quad 0 / 282890$ & $4 / 846268$ \\
\hline AGR2 & $90 / 151938$ & $45 / 643586$ & $117 / 65595$ & $342 / 448716$ & $133 / 74783$ & $36 / 189999$ & $3 / 44571 \quad 0 / 282890$ & $0 / 846268$ \\
\hline $\mathrm{LCN} 2$ & $48 / 170084$ & $53 / 643586$ & $17 / 70532$ & $165 / 448716$ & $60 / 75487$ & 213/189999 & $2 / 44611 \quad 90 / 282890$ & $2 / 846268$ \\
\hline EFNB1 & $30 / 170084$ & $21 / 643586$ & $1 / 70532$ & $28 / 448716$ & $9 / 75487$ & 7/189999 & $0 / 44611 \quad 2 / 282890$ & $11 / 846268$ \\
\hline ASS1 & $62 / 170084$ & $147 / 643586$ & $17 / 70532$ & $41 / 448716$ & $20 / 75487$ & $16 / 189999$ & $0 / 44611 \quad 0 / 282890$ & $3 / 846268$ \\
\hline LGALS4 & $93 / 170084$ & $56 / 643586$ & $18 / 70532$ & $232 / 448716$ & $8 / 75487$ & $46 / 189999$ & $0 / 44611 \quad 0 / 282890$ & $1 / 846268$ \\
\hline MGC3047 & $1 / 170084$ & $0 / 643586$ & $2 / 70532$ & $9 / 448716$ & $6 / 75487$ & 8/189999 & $0 / 44611 \quad 0 / 282890$ & $0 / 846268$ \\
\hline CLDN3 & $152 / 170084$ & $80 / 643586$ & $6 / 70532$ & $96 / 448716$ & $1 / 75487$ & 29/189999 & $0 / 44611 \quad 0 / 282890$ & $7 / 846268$ \\
\hline S100A16 & $46 / 170084$ & $164 / 643586$ & $5 / 70532$ & $73 / 448716$ & $20 / 75487$ & $66 / 189999$ & $2 / 44611 \quad 0 / 282890$ & $1 / 846268$ \\
\hline S100A6 & $65 / 151938$ & $506 / 643586$ & $49 / 65595$ & $656 / 448716$ & $68 / 74783$ & $480 / 189999$ & $3 / 44571 \quad 77 / 282890$ & $625 / 846268$ \\
\hline GNT-V & $4 / 151938$ & $2 / 643586$ & $1 / 65595$ & $0 / 448716$ & $0 / 74783$ & $0 / 189999$ & $0 / 44571 \quad 0 / 282890$ & $0 / 846268$ \\
\hline EGFR & $7 / 151938$ & $1 / 643586$ & $3 / 65595$ & $2 / 448716$ & $0 / 74783$ & 0/189999 & $0 / 44571 \quad 0 / 282890$ & $0 / 846268$ \\
\hline
\end{tabular}

Each column represents the number of ESTs or SAGE tags corresponding to the gene divided by the total number of ESTs or SAGE tags in all libraries with the given tissue/histology. Only SAGE data are available for white cells blood. PKP3, plakophilin 3; AGR2, anterior gradient homolog 2; LCN2, lipocalin 2 (oncogene 24p3); EFNB1, ephrin-B1; ASS1, argininosuccinate synthetase; LGALS4; lectin, galactoside-binding, soluble, 4 (galectin 4); MGC3047, hypothetical protein, MXRA8; CLDN3, claudin 3; S100A16, S100 calcium binding protein A16; S100A6, S100 calcium binding protein A6 (calcyclin); GNT-V, beta-1,6- $N$ acetylglucosaminyltransferase V, MGAT 5; EGFR, epidermal growth factor receptor.

\subsection{Experimental validation of the in silico data: $q R T-P C R$ in cell lines}

Criteria to select molecular markers identified by bioinformatic approach for quantitative real-time PCR studies are described in "Section 2.1". In brief, we select those novel markers with absent or low expression in blood and bone marrow-derived EST libraries and high expression in gastrointestinal cancer-derived EST libraries. In addition functional annotations based on Gene Ontology and related with epithelial cellular components or (potentially) with metastatic process [22] were taken into account.

In this way, we chose PKP3, AGR2, LCN2, S100A16, S100A6, EFNB1, ASS1, LGALS4, MGC3047/MXRA8, and CLDN3 for further experimental validation.

Interestingly PKP3, LGALS4, CLDN3, and EFNB1 were involved in cell adhesion, following biological process annotations in Gene Ontology. S100A6 and S100A16 are related in calcium-dependent protein binding. ASS1 has argininosuccinate synthase activity. No significantly overrepresented GO annotations were found for AGR2, LCN2 and MGC3047/MXRA8.

The expression of these selected markers was compared against EGFR and GNT-V, both described as overexpressed in gastrointestinal cancer. The expression levels of these genes were measured in 10 gastrointestinal tumor cell-lines (eight colorectal tumor cell-lines, one gastroesophageal cell-line, and one pancreatic cell-line). The values obtained were compared against three hematopoietic tumor cell-lines (Jurkat, K562, and KG1) and three different pools of normal bone marrow that include 23 individual samples. All selected genes assessed showed higher expression levels in gastrointestinal tumor cell-lines than in normal human bone marrow with two exceptions, LCN2 and MGC3047 (Fig. 2). LCN2 showed lower expression levels in all gastrointestinal tumor cell-lines tested than normal human bone marrow. MGC3047 only showed higher expression levels over to those obtained with normal human bone marrow in OJC1 pancreatic tumor cell-line. The rest of the markers showed high expression in at least 7-10 
gastrointestinal tumor cell-lines than in normal human bone marrow. Also, S100A16 was the unique marker assessed that showed higher expression levels than normal human bone marrow in all tumor celllines tested. Although GNT-V was expressed in 8 out of 10 cell digestive cancer cell-lines, its values were together with LCN2, EFNB1, ASS1, and MGC3047, the ones that showed the lowest expression in the tumor cell-lines assessed and they were not selected for blood mRNA quantification.

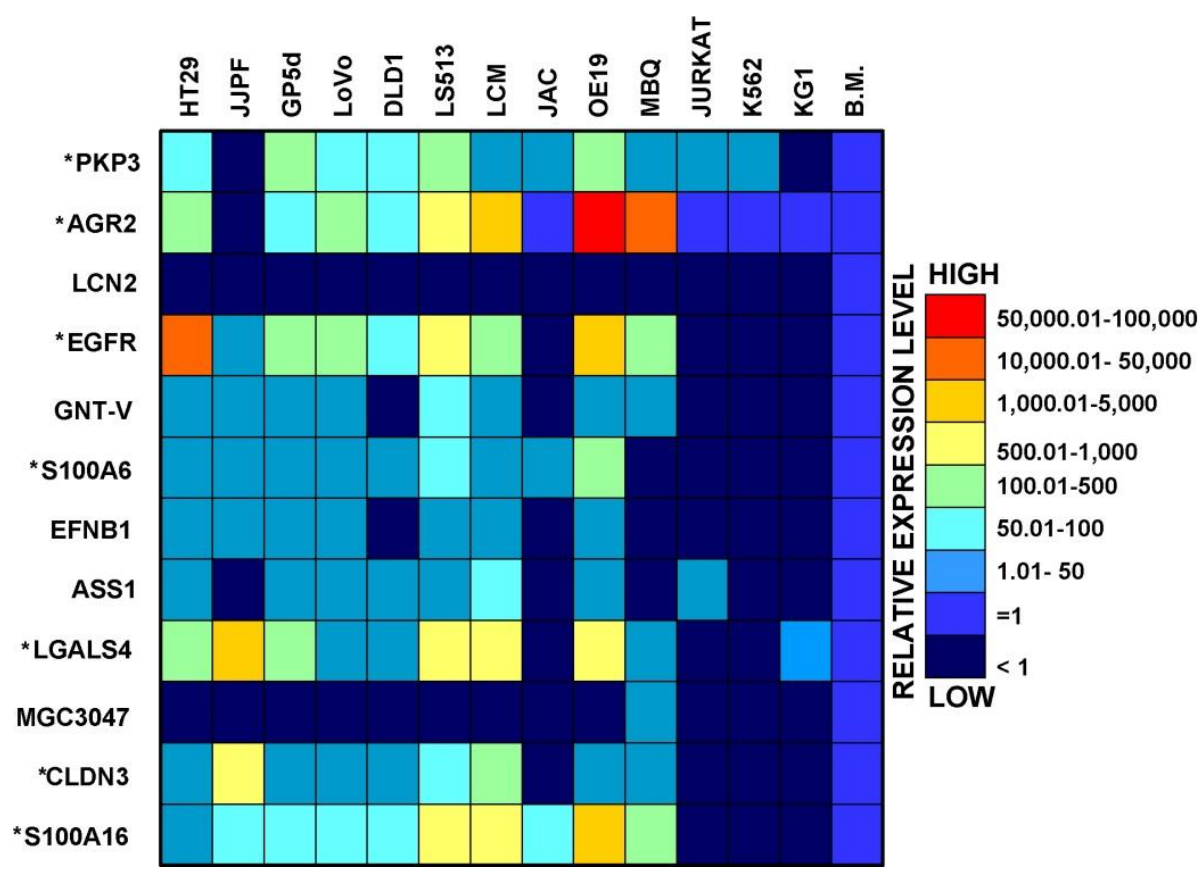

Fig. 2. Expression profile in cell-lines and normal human bone marrows: heat-map showing relative mRNA expression of in silico selected genes (rows) in cell-lines and bone marrow (columns). mRNA relative expression were measured by qRT-PCR. Results are the mean of at least three independent measurements. Data were normalized $v s$. the values obtained in human normal bone marrow. Relative expression levels are shown in a color scale. Genes are described in Table 3. Cell-lines (columns) are as shown: colorectal cancer (Gp5d, LoVo, DLD1, LS513, HT29, OJC4, OJC5, OJC6); gastric adenocarcinoma (OE19); pancreatic carcinoma (OJC1); hematopoietic (Jurkat, KG1 and K562); normal human bone marrows (BM). *Indicated those genes selected for their mRNA quantification in blood samples from patients.

Among all the genes assessed, PKP3, AGR2, S100A16, S100A6, LGALS4, and CLDN3 showed the most highly expression values with regard to normal human bone marrow.

\section{3. mRNA quantitative detection of selected genes in peripheral blood from patients with gastrointestinal} cancer and controls

We chose PKP3, AGR2, S100A6, S100A16, LGALS4, and CLDN3 for mRNA quantitative detection in peripheral blood samples from gastrointestinal cancer patients and controls. All of them showed an expression up to $10^{2}$ - to $10^{5}$-fold higher in tumor cell-lines than in normal human bone marrow. Also, EGFR mRNA expression was measured in blood samples in order to compare their results with those obtained with the mRNA markers selected. All of these were expressed in at least 8 out of 10 tumor celllines. 
Among the six potential molecular markers assessed in-patient and matched control blood samples, PKP3 and AGR2 showed the most remarkable results (Table 5 and Fig. 3). Values for PKP3 and AGR2 mRNA were significantly higher in blood samples from gastrointestinal cancer patients than in blood samples from non-carcinoma patients with a significant level of $p=0.000$ and 0.019 , respectively (MannWhitney $U$-test).

Table 5. Median relative expression levels and ratios of candidate mRNA markers of circulating tumor cells in patients and controls blood

\begin{tabular}{lllll}
\hline Gene name & Gene symbol & Patients blood & Controls blood & Patients: controls \\
\hline & & & & \\
Plakophilin 3 & PKP3 & 175.42 & 9.32 & 18.82 \\
Anterior gradient 2 & $A G R 2$ & 13.50 & 0 & $*$ \\
Claudin 3 & CLDN3 & 8040.27 & 29,299 & 2.74 \\
Galectin 4 & LGALS4 & 27,073 & 13,070 & 2.07 \\
S100 calcium binding protein A6 (calcyclin) & S100A6 & 53,840 & 58548.6 & 0.92 \\
S100 calcium binding protein A16 & S100A16 & 41,945 & 23,090 & 1.82 \\
Epidermal growth factor receptor & EGFR & 67.22 & 24.64 & 2.72 \\
& & & & \\
\hline
\end{tabular}

mRNA levels were measured by qRT-PCR as described in Section 2. Results are the mean of at least three independent measurements. *There was no AGR2 expression in normal bloods.

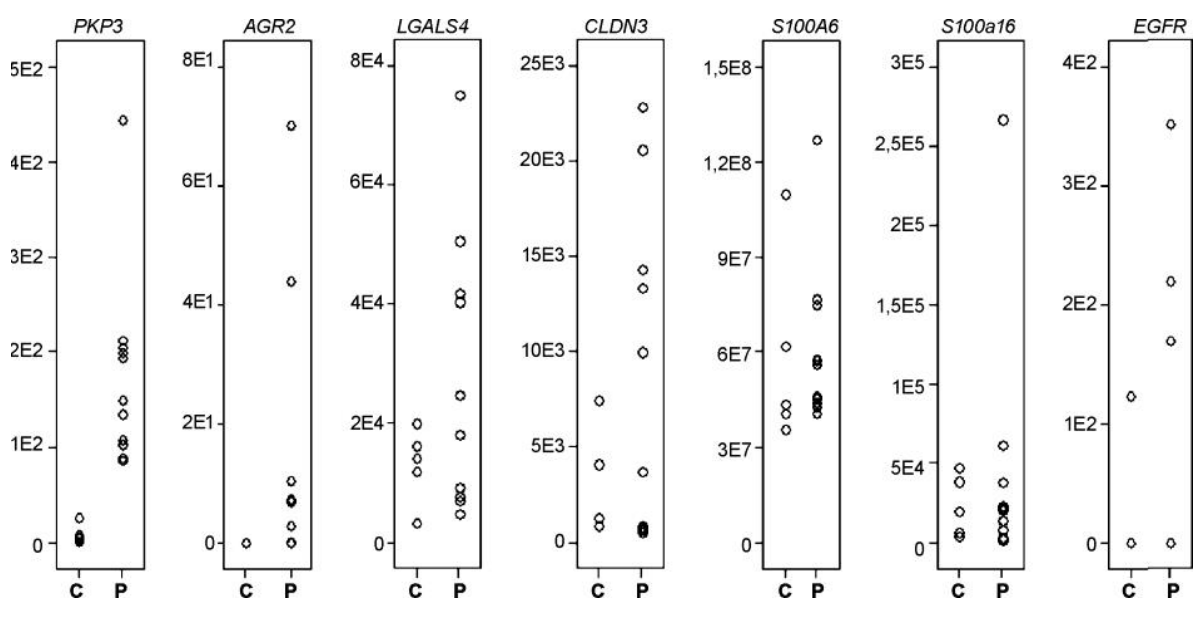

Fig. 3. mRNA expression levels of PKP3, AGR2, LGALS4, CLDN3, S100A6, S100A16 and EGFR mRNA in peripheral blood: mRNA expression levels of PKP3, AGR2, LGALS4, CLDN3, S100A6, S100A16 and EGFR mRNA ( $Y$-axis) determined in peripheral blood from non-carcinoma patients $(C)$ and patients $(\mathrm{P})$ with gastrointestinal cancer $(X$-axis). mRNA levels were measured by qRTPCR as described in Section 2. Results are the mean of at least three independent measurements.

ROC curve analysis showed that the area under the ROC curve for PKP3 mRNA relative expression levels was 1.00 (S.E. $=0.00 ; p=0.002)$. Optimal sensitivity $(100 \%)$ and specificity $(100 \%)$ was obtained by applying 56.61 as a PKP3 mRNA R.E.L. cutoff value. 
In the case of AGR2, ROC curve analysis showed that the area under the ROC curve for AGR2 mRNA relative expression levels was 0.864 (S.E. $=0.092 ; 95 \%$ confidence range $0.683-1.045 ; p=$ 0.023). Optimal sensitivity (72.7\%) and specificity (100\%) was obtained by applying 0.044 as AGR2 mRNA R.E.L. cutoff value. In both cases, the calculated cutoff value may be useful to define positive or negative results and it discriminates samples of peripheral blood from patients with gastrointestinal cancer and control donors.

Area under the ROC curve for EGFR mRNA relative expression levels was 0.564 (S.E. $=0.151 ; 95 \%$ confidence range $0.268-0.859 ; p=0.692$ ). Thus, in our series, EGFR mRNA amplification was not useful to differentiate between carcinoma patients and controls. In relation to the other four potential molecular markers assessed, S100A6, S100A16, LGALS4, and CLDN3, neither of them could be considered specific enough to detect circulating tumor cells. Perhaps increasing the number of samples analyzed and ROC curve analysis, or using logistic regression to determine a combination equation using all six molecular markers assessed could yield a stronger and powerful diagnostic discrimination test.

PKP3 and AGR2 seem to be two new promising molecular markers for qRT-PCR detection of circulating tumor cells in peripheral blood samples from gastrointestinal cancer patients. Our findings had improved the previous results obtained with other common markers, widely used in micrometastasis detection, such as EGFR.

\section{4. mRNA detection of selected genes in colon cancer samples}

To validate the DDD data and the results obtained in cell-lines, we further investigated the mRNA expression of the genes PKP3, AGR2, LGALS4, and CLDN3 in colon cancer samples. These genes exhibited up-regulated expression based on both in silico data and GI cancer cell-lines qRT-PCR results. Absolute quantification by real-time RT-PCR analysis using RNA isolated from FFPE was used. Patient samples included primary colon tumors $(n=14)$. In addition metachronous metastatic lesions (hepatic and peritoneal) excised from two of these patients were studied.

Among all of the markers tested, CLDN3 showed expression in a large number of tissues analyzed (90.9\%) followed by AGR2 (81.8\%), LGALS4 (45.4\%), and PKP3 (40\%). For PKP3, there was no concordant mRNA expression between primary and metastasis in the cases studied, suggesting a dynamic regulation of their expression during tumor progression.

\section{Discussion}

Metastatic hematogenous spreading is one of the most important factors affecting the prognosis of carcinoma patients, including gastrointestinal cancer. Detection of carcinoma cells in the blood or minimal deposits in distant organs as bone marrow could be important to identify patients at high risk of relapse or disease progression [7]. PCR amplification of tissue or tumor-selective mRNA is the most powerful tool for surrogate detection of this isolated tumor cells. However, specificity of different mRNA-based assays has been controversial and there is a need for a systematic evaluation for each new biomarker proposed.

Our research aimed to identify, at first, a set of specific epithelial gene markers highly expressed in gastrointestinal cancer. Electronic databases analysis allowed us to obtain a list of genes that are differentially expressed, to the point of statistical significance, in colon, pancreas, and gastric libraries. We hypothesized that these transcripts could represent the molecular signature associated with CTC. Global gene expression profile of cancer cells isolated from blood has been recently described in colon, breast, and prostatic tumors, using an immunomagnetic enrichment and microarray analysis [23]. In a recent report, Solmi et al. [24] have used a microarray-based high-throughput screening method to identify candidate marker mRNAs for CTC detection. However, employing a conventional RT-PCR procedure they could not find a set of suitable and consistent mRNA marker for detection of colonic cells 
in the blood. In previous reports using both in silico data-mining tools and conventional RT-PCR, these authors [25] suggest that among 15 genes differentially expressed in colon, only non-SMC structural maintenance of chromosomes, element 1 protein (NSE1) and gastrin (GAS) mRNAs could be suitable for detection of circulating colon cancer cells in blood.

To point out the validity of our results using an in silico approach, our set of overexpressed genes included different markers previously used for CTC detection. In addition, AGR2 and different S100 proteins were identified in our work as well as in the CTC molecular profile proposed by Smirnov et al. [23].

To obtain independent evidence to support the bioinformatics-approach for selecting CTC markers, quantitative mRNA expression of selected genes were analyzed in gastrointestinal cell-lines, hematopoietic cell-lines, and normal bone marrows. In order to validate their usefulness as potential molecular markers for gastrointestinal disseminated tumor cell detection, these results were compared with those obtained for EGFR and GNT-V.

Among all the genes assessed, PKP3, AGR2, S100A16, S100A6, LGALS4, and CLDN3 showed the most highly expressed values with regard to normal human bone marrow. For this reason they were chosen for further analysis for their expression in blood from gastrointestinal cancer patients and controls. One of the main problems with any mRNA-based assays is the illegitimate transcription of the so-called "epithelial specific transcripts" in hematopoietic compartment [[2], [3], [4]]. In our study, we included a quantitative RT-PCR approach and a significant number of controls samples ( 23 bone marrows and 10 bloods) in order to select the most specific mRNA markers.

In patient blood samples, qRT-PCR for PKP3 and AGR2 showed the most promising results. We could calculate an mRNA R.E.L. cutoff value of 56.61 and 0.044 for PKP3 and AGR2, respectively. These cut-off points may be useful to distinguish between samples of peripheral blood from gastrointestinal cancer patients and control samples. However, we need to underscore that all of the patients included in our series of blood samples were in advanced disease status. To better evaluate the predictive and prognostic role (if any) of PKP3 and AGR2 qRT-PCR assays in blood, a prospective study with a larger number, and less advanced, cancer patients are clearly needed.

When we compared our results obtained for PKP3 and AGR2 with those obtained for EGFR, our findings suggest that PKP3 and AGR2 could be better for its use as surrogate markers for circulating tumor cells detection in patients with GI cancer.

This is the first time that PKP3, a member of the p120ctn/plakophilin subfamily of armadillo proteins, is suggested as a molecular marker for CTC detection. PKP3 is present in desmosomes of epithelial cells and binds all three desmogleins, desmocollin, plakoglobin, desmoplakin, and the epithelial keratin 18. This protein not only functions in desmosome-dependent cell adhesion, but in signaling transduction [[26], [27], [28]].

In view of the importance of $\beta$-catenin and other armadillo proteins in tumor biology, it is surprising that up to now, knowledge about the occurrence of PKPs in tumors is limited and little is known about their possible biologic role in tumor invasion and metastasis [29]. Recent studies had shown evidences that PKP3 protein may serve as useful marker for predicting the clinical outcome of head and neck tumors [30] and non-small cell lung cancer [31]. Other investigators [32] had demonstrated that this protein is highly expressed in various types of adenocarcinomas (colorectal, pancreatic, and prostate). In our work, PKP3 mRNA was highly expressed in digestive cancer cell-lines (8/10) but less in colon cancer samples (40\%). One limitation of our analysis was the use of RNA isolated from FFPE. Recently, we studied PKP3 protein by immunohistochemistry in a large set of digestive tumors and found its expression in $66.7 \%$ of cases [33]. Aigner et al. have shown that PKP3 is repressed in the epithelial to mesenchymal transition of tumors under control by the E-cadherin repressor ZEB1 [34]. These data suggest, as previously stated [23] that gene expression signatures of CTCs may change as the disease progresses. In 
addition, selective suppression of gene transcription was one of the characteristics of the molecular signature associated with bone marrow micrometastasis in breast cancer [35].

In relation with AGR2, the human homolog of Xenopus anterior gradient 2 (XAG2), our results corroborated and complemented a previous study in which it has been postulated as a marker for detection of circulating tumor cells in peripheral blood of advanced cancer patients [23]. AGR2 mRNA is expressed in several normal human tissue types that are rich in epithelial cells, including colon, pancreas, lung, stomach, rectum, prostate, and breast [[36], [37], [38]]. AGR2 has been demonstrated to be upregulated not only in hormonal-dependent tumors as breast, endometrial, renal, and prostate cancers but also in lung carcinomas [39]. Using qRT-PCR analysis, we demonstrated an increased AGR2 expression in gastrointestinal cancer cell-lines and colon tumors. Although AGR2 function is not known, experimental data suggest that it could act as a survival factor through inhibition of $\mathrm{p} 53$, and enhancing tumor cell adhesion to substratum [[40], [41]].

However, identification of truly specific markers is a difficult task. Our quantitative RT-PCR assay demonstrated background expression in blood derived from non-tumor donors for S100A16, S100A6, LGALS4, and CLDN3. Although these gene transcripts were found highly expressed in cancer specimens, none of them could be considered specific enough, at first, for circulating epithelial cells detection. Their value in multigene qRT-PCR approach as a discrimination test could be analyzed using logistic regression and ROC curve.

In conclusion, novel and known gastrointestinal-specific mRNA markers for circulating tumor cells have been identified through in silico analysis and validated in clinical material. Our results indicate that quantitative real-time reverse transcription-PCR assay targeted to PKP3 and AGR2 mRNAs might be helpful to detect circulating tumor cells in patients with gastrointestinal cancer.

\section{Conflict of interest}

None declared.

\section{Acknowledgements}

This study was supported by grant 5090252501 from Universidade da Coruña. S. Díaz-Prado is supported by an Isidro Parga Pondal research contract by Xunta de Galicia (A Coruña, Galicia, Spain). Cancer research in our laboratory is supported by the "Fundación Juan Canalejo-Marítimo de Oza". We thank the CGAP database for providing access and the data-mining tools used in this study.

\section{References}

1. Coleman, M.P., Gatta, G., Verdecchia, A., Esteve, J., Sant, M., Storm, H. et al. EUROCARE-3 summary: cancer survival in Europe at the end of the 20th century. Ann Oncol. 2003; 14: v128-v149

2. Vlems, F.A., Diepstra, J.H.S., Cornelissen, I.M.H.A., Ruers, T.J., Ligtenberg, M.J., Punt, C.J. et al. Limitations of cytokeratin 20 RT-PCR to detect disseminated tumour cells in blood and bone marrow of patients with colorectal cancer: expression in controls and downregulation in tumour tissue. Mol Pathol. 2002; 55: 156-163

3. Dandachi, N., Balic, M., Stanzer, S., Halm, M., Resel, M., Hinterleitner, T.A. et al. Critical evaluation of real-time reverse transcriptase-polymerase chain reaction for the quantitative detection of cytokeratin 20 mRNA in colorectal cancer patients. J Mol Diagn. 2005; 7: 631637

4. Schuster, R., Max, N., Mann, B., Heufelder, K., Thilo, F., Gröne, J. et al. Quantitative realtime RT-PCR for detection of disseminated tumor cells in peripheral blood of patients with colorectal cancer using different mRNA markers. Int J Cancer. 2004; 108: 219-227

5. Bustin, S.A. and Mueller, R. Real-time reverse transcription PCR (qRT-PCR) and its potential use in clinical diagnosis. Clin Sci (Lond). 2005; 109: 365-379 
6. Salomon, D.S., Brandt, R., Ciardiello, F., and Normanno, N. Epidermal growth factorrelated peptides and their receptors in human malignancies. Crit Rev Oncol Hematol. 1995; 19: $183-232$

7. Pantel, K. and Alix-Panabieres, C. The clinical significance of circulating tumor cells. Nat Clin Pract Oncol. 2007; 4: 62-63

8. Sugita, Y., Fujiwara, Y., Hoon, D.S., Miyamoto, A., Sakon, M., Kuo, C.T. et al. Overexpression of beta 1,4- $\mathrm{N}$-acetylgalactosaminyl-transferase mRNA as a molecular marker for various types of cancers. Oncology. 2002; 62: 149-156

9. Murata, K., Miyoshi, E., Kameyama, M., Ishikawa, O., Kabuto, T., Sasaki, Y. et al. Expression of $\mathrm{N}$-acetylglucosaminyl transferase $\mathrm{V}$ in colorectal cancer correlates with metastasis and poor prognosis. Clin Cancer Res. 2000; 6: 1772-1777

10. Pepe, M.S., Etzioni, R., Feng, Z., Potter, J.D., Thompson, M.L., Thornquist, M. et al. Phases of biomarker development for early detection of cancer. J Natl Cancer Inst. 2001; 93: $1054-1061$

11. UniGene [database on the Internet]. Bethesda: National Library of Medicine (US); [cited Jan 22, 2006]. Digital Differential Display (DDD). Homo sapiens. Available from http://www.ncbi.nlm.nih.gov/UniGene/ddd.cgi?ORG=Hs.

12. Cancer Genome Anatomy Project [database on the Internet]. Bethesda (MD): National Cancer Institute (US); [cited December 15, 2005]. GeneFinder. Available from http://cgap.nci.nih.gov/Genes/GeneFinder.

13. Lal, A., Lash, A.E., Altschul, S.F., Vekulescu, V., Zhang, L., McLendon, R.E. et al. A public database for gene expression in human cancers. Cancer Res. 1999; 59: 5403-5407

14. Cancer Genome Anatomy Project [database on the Internet]. Bethesda (MD): National Cancer Institute (US); [cited December 15, 2005]. Tissues. Virtual Northern. EGFR. Available from http://cgap.nci.nih.gov/Tissues/VirtualNorthern?TEXT=0\&ORG=Hs\&CID=488293.

15. Cancer Genome Anatomy Project [database on the Internet]. Bethesda (MD): National Cancer Institute (US); [cited December 15, 2005]. Tissues. Virtual Northern. MGAT5. Available from http://cgap.nci.nih.gov/Tissues/VirtualNorthern?TEXT=0\&ORG=Hs\&CID=651869.

16. Cancer Genome Anatomy Project [database on the Internet]. Bethesda (MD): National Cancer Institute (US); [cited December 15, 2005]. GoBrowser. Available from http://cgap.nci.nih.gov/Genes/GOBrowser.

17. Valladares Ayerbes, M., Calvo, L., Alonso, G., Iglesias, P., Lorenzo, M.J., Brandón, I. et al. Evaluation of messenger RNA of pituitary tumour-transforming gene-1 (PTTG1) as a molecular marker for micrometastasis. in: J.J. Li, S.A. Li, A. Llombart-Bosch (Eds.) Hormonal carcinogenesis IV. Springer-Verlag, New York; 2005: 462-468

18. Roche Applied Science [database on the Internet] [cited December 20, 2005]. Assay Design Center/ProbeFinder. Homo sapiens (Human). Available from http://www.universalprobelibrary.com.

19. Roche Applied Science [database on the Internet] [cited December 20, 2005]. Universal ProbeLibrary. Universal ProbeLibrary interest site. Assay Design Center/ProbeFinder. Homo sapiens (Human). Available from http://www.roche-applied-science.com.

20. Livak, K.J. and Schmittgen, T.D. Analysis of relative gene expression data using real-time quantitative PCR and the $2^{-\Delta \Delta C t}$ method. Methods. 2001; 25: 402-408

21. Vogel, I. and Kalthoff, H. Clinical relevance of tumor cell dissemination in colorectal, gastric and pancreatic carcinoma. in: K. Pantel (Ed.) Micrometastasis. Kluwer Academic Publishers, Dordrecht; 2003: 139-172

22. Gupta, G.P. and Massague, J. Cancer metastasis: building a framework. Cell. 2006; 127: 679-695

23. Smirnov, D.A., Zweitzig, D.R., Foulk, B.W., Miller, M.C., Doyle, C.V., Piente, K.J. et al. Global gene expression profiling of circulating tumor cells. Cancer Res. 2005; 65: 49934997

24. Solmi, R., Ugolini, G., Rosati, G., Zanotti, S., Lauriola, M., Montroni, I. et al. Microarraybased identification and RT-PCR test screening for epithelial-specific mRNAs in peripheral blood of patients with colon cancer. BMC Cancer. 2006; 6: 250

25. Solmi, R., De Sanctis, P., Zucchini, C., Ugolini, G., Rosati, G., del Governatore, M. et al. Search for epithelial-specific mRNAs in peripheral blood of patients with colon cancer by RT-PCR. Int J Oncol. 2004; 25: 1049-1056

26. Bonne, S., van Hengel, J., Nollet, F., Kools, P., and van Roy, F. Plakophilin-3, a novel armadillo-like protein present in nuclei and desmosomes of epithelial cells. J Cell Sci. 1999; 112: $2265-2276$ 
27. Schmidt, A., Langbein, L., Prätzel, S., Rode, M., Rackwitz, H.R., and Franke, W.W. Plakophilin 3-a novel cell-type-specific desmosomal plaque protein. Differentiation. 1999; 64: 291-306

28. Bonné, S., Gilbert, B., Hatzfeld, M., Chen, X., Green, K.J., and Van Roy, F. Defining desmosomal plakophilin-3 interactions. J Cell Biol. 2003; 161: 403-416

29. Brembeck, F.H., Rosario, M., and Birchmeier, W. Balancing cell adhesion and Wnt signaling, the key role of beta-catenin. Curr Opin Genet Dev. 2006; 16: 51-59

30. Papagerakis, S., Shabana, A.H., Depondt, J., Gehanno, P., and Forest, N. Immunohistochemical localization of plakophilins (PKP1, PKP2, PKP3, and p0071) in primary oropharyngeal tumors: correlation with clinical parameters. Hum Pathol. 2003; 34: $565-572$

31. Furukawa, C., Daigo, Y., Takano, A., Ishikawa, N., Kato, T., Hayama, S. et al. Plakophilin 3 oncogene as prognostic marker and therapeutic target for lung cancer. Cancer Res. 2005; 65: 7102-7110

32. Schwarz, J., Ayim, A., Schmidt, A., Jäger, S., Koch, S., Baumann, R. et al. Differential expression of desmosomal plakophilins in various types of carcinomas: correlation with cell type and differentiation. Hum Pathol. 2006; 37: 613-622

33. Valladares-Ayerbes M, Díaz S, Medina V, Iglesias P, Lorenzo MJ, Santamarina I, et al. Evaluation of plakophilin 3 as a molecular marker for micrometastasis in gastrointestinal cancer. In: Grunbag SM, editor. Proceedings of the gastrointestinal cancer symposium; January 19-21, 2007; Orlando, USA. American Society of Clinical Oncology; 2007. p. 302 [Abstract 438]

34. Aigner, K., Descovich, L., Mikula, M., Sultan, A., Schreiber, M., Mikulits, W. et al. The transcription factor ZEB1 (dEF1) represses plakophilin 3 during human cancer progression. FEBS Letters. 2007; 581: 1617-1624

35. Woelfle, U., Cloos, J., Sauter, G., Riethdorf, L., Janicke, F., Van Diest, P. et al. Molecular signature associated with bone marrow micrometastasis in human breast cancer. Cancer Res. 2003; 63: 5679-5684

36. Zhang, J.-S., Gong, A., Cheville, J.C., Smith, D.I., and Young, C.Y.F. AGR2, an androgeninducible secretory protein overexpressed in prostate cancer. Genes Chromosomes Cancer. 2005; 43: 249-259

37. Fritzsche, F.R., Dahl, E., Pahl, S., Burkhardt, M., Luo, J., Mayordomo, E. et al. Prognostic relevance of AGR2 expression in breast cancer. Clin Cancer Res. 2006; 12: 1728-1734

38. Lee, S., Bang, S., Song, K., and Lee, I. Differential expression in normal-adenomacarcinoma sequence suggests complex molecular carcinogenesis in colon. Oncol Rep. 2006; 16: 747-754

39. Hong Zhu, H., Lam, D.C., Han, K.C., Tin, V.P., Suen, W.S., Wang, E. et al. High resolution analysis of genomic aberrations by metaphase and array comparative genomic hybridization identifies candidate tumour genes in lung cancer cell lines. Cancer Lett. 2007; 245: 303-314

40. Pohler, E., Craig, A.L., Cotton, J., Lawrie, L., Dillon, J.F., Ross, P. et al. The Barrett's antigen anterior gradient-2 silences the p53 transcriptional response to DNA damage. Mol Cell Proteomics. 2004; 3: 534-547

41. Liu, D., Rudland, P.S., Sibson, D.R., Platt-Higgins, A., and Barraclough, R. Human homologue of cement gland protein, a novel metastasis inducer associated with breast carcinomas. Cancer Res. 2005; 65: 3796-3805 